\title{
Current Trends of Nursing Doctoral Education in Europe
}

\author{
Hugh P. McKenna ${ }^{1}$ \\ 1 Medical School Development, Ulster University, United Kingdom \\ hp.mckenna@ulster.ac.uk
}

\begin{abstract}
Background: Nursing doctoral education has advanced nursing science and provided a basis for evidence-based nursing practice in Europe. Purpose: To describe my perspective on the current trends of nurse doctoral education in Europe and offer suggestions for African nursing doctoral education. Methods: The development of nursing doctorates in Europeis explored and compared briefly with that of the USA. Results/Observation: Three differentapproaches to doctoral education in Europe are traditional $\mathrm{PhD}$, professional doctorates and doctorates by publish works, and theymerit careful examination for nursing doctoral education in Africa. Conclusion: From the lessons learned in European doctoral education for nursing, the traditional $\mathrm{PhD}$ programme would be the most appropriate model for Africa. However, for this to happen there needs to be capacity building to establish a critical mass of properly credentialed faculty members with active programs of funded research, international collaborations and publications in high quality peer reviewed journals.
\end{abstract}

\section{Introduction}

The progression through doctorate studies for US nurses had three stages. In the early part of the $20^{\text {th }}$ century Doctorates of Education (Ed.D) were popular with nurses, later Doctorates of Nursing Science (DNSc) programmes, followed by $\mathrm{PhD}$, which has become the mainstay of nursing doctoral education in the US. In contrast, European doctoral education for nurses did not go through the first of these stages; rather, it commenced with nurses undertaking $\mathrm{PhDs}$ in other disciplinary fields, such as sociology and psychology. In the late 1970s, the number of European nurses who had doctorates in nursing (and professors of nursing incidentally) was small. It is only in the 1990s that nurses began undertaking nursing doctorates in what could be perceived as reasonable numbers. In the UK for instance, Professor Michael Traynor from Middlesex University, United Kingdom, estimated that in 1997, there were around $300 \mathrm{PhD}$ theses in the Royal College of Nursing's Library in London. While these represented doctoral research carried out by nurses, not all were $\mathrm{PhDs}$ in nursing. Contemporaneously, in mainland Europe, there were some nurses qualified at doctoral level, but few possessed nursing doctorates.

The origins of the traditional European $\mathrm{PhD}$ go back to the Middle Ages. It is not a taught course; rather, the student spends 3-4 years full time or 5-7 years part time focusing entirely on producing a thesis based upon a single research project. During that time, suitable prepared members of academic faculty/staff (often two supervisors) will guide the student. These supervisors must possess a $\mathrm{PhD}$ and at least one of them must have supervised a doctoral student to successful completion. They meet with the student for supervisory sessions approximately 1-2 hours per month. The student does not normally attend any classes, undertake examinations or submit course work. However, they may attend two or three in-house research seminars per year on topics such a methodology, statistics, grant writing and publishing. The entire focus of the $\mathrm{PhD}$ is research training culminating in the production of a 100,000word thesis. In essence, there are three outcomes:

- sustained independent effort on the part of the student;

- rigorous and systematic research training; and

- a confirmed contribution to the body of knowledge in the field.

The importance of doctoral education for nursing In the 1990s, governments across Europe were calling for nurses to demonstrate evidenced-based practice 
for clinical effectiveness.[1] However, it is difficult to achieve this objective if nursing as a discipline is not developed at an advanced level, and this cannot happen if nurses themselves are not developed at an advanced level! Therefore, in the $21^{\text {st }}$ century, nursing requires a cadre of scholars educated to doctoral level who will focus upon the essence of nursing, its generation and testing. There was no doubt that the rigorous preparation of doctorally prepared nursing is among the most important and pressing educational issues facing our profession today and in the future. It is upon this group of nurses that the profession must depend for the critical and creative study of the science and practise of nursing.

At its best, a doctoral programme is one where knowledge is generated, challenged, tested as well as being transmitted.[2] In those countries where nurses have been delayed in gaining admission to doctoral programmes, the development of nursing knowledge has also been delayed. Nursing in many developing countries has a long way to go; many of those who are managing nursing programmes have not undergone an educational process of this nature. In fact, nurse teachers are often inadequately prepared to teach at doctoral level and it is questionable whether those nurses who have a doctorate in another discipline are able and perhaps willing to explore and enhance what is the essence of nursing. Faculty's research should be theoretically and philosophically relevant to the phenomena of interest to nursing. A range of staff undertaking unrelated non-cumulative studies in a plethora of topics with no clear focus is not a good milieu for doctoral study. Furthermore, a doctoral programme that has the prefix 'nursing' is guilty of a misrepresentation if it ignores the importance of science driving practice to ensure improved patient care.

\section{Taught doctorates in Nursing}

At the end of the $20^{\text {th }}$ century, much discussion was taking place in Europe on the introduction of what were called 'professional' or 'taught doctorates', such as the Doctor of Nursing Science (DNSc) programme. There were a number of criticisms of research $\mathrm{PhDs}$ driving these discussions.

- Many practising nurses perceive $\mathrm{PhD}$ study as completely divorced from the real world of nursing and not likely to affect them or their patients directly. To them, the traditional research $\mathrm{PhD}$ did little to foster the link between research, theory and practice.

- The PhD was seen as an infatuation with science to the detriment of the substance of discipline like nursing. The argument went something like this - nurses are nurses, not architects nor engineers; therefore, nursing's doctoral programmes should demonstrate that nursing knowledge, nursing scholarship and the essence of nursing has equal weight with research methods and techniques.

- Unlike highly structured professional doctorates, where nurses are taught in a group and they have coursework and examinations, the $\mathrm{PhD}$ was seen as a lonelier approach to gaining a doctorate. Apart from regular meeting with their supervisors, $\mathrm{PhD}$ students often worked in relative isolation.

\section{University of Ulster's DNSc}

The first DNSc programme in Europe commenced in 1994 at the University of Ulster; shortly after its inception, I was appointed as its course director. The establishment of this programme was a laborious process that included different layers of stringent validation and review. It was introduced in an effort to address some of the criticisms outlined above.

The educational challenge was not unlike that for our $\mathrm{PhD}$ students. Our desire was to endow them with a clear sense of purpose and a lifetime love for expanding their intellectual horizons with regard to the practice of nursing. The goal was to recognise themselves as emergent scientists and appreciate the significance of the development of scholarly endeavours. We also wanted to provide them with the ability to think critically, identify the gaps in nursing knowledge, the search for truth without prejudice, to take risks with ideas, and to be creative and imaginative in solving clinical problems. In addition, they should be willing and able to clearly present ideas to their contemporaries and accept critical comments without intense feelings of personal attack.

\section{DNSc versus PhD; a European perspective}

In the US, the DNSc programme was introduced because as an early entrant into higher education, nursing could not offer PhDs. Later, when the universities or higher education councils approved $\mathrm{PhD}$ programmes, these nursing schools converted to $\mathrm{PhDs}$ with little curricular changes. In fact, the DNSc alumni of some schools were given the option to change their degree to $\mathrm{PhD}$ retrospectively. There were many similarities between 
these two programmes.

In Europe, there are clear differences between the PhDs and the DNSc. The major differences are in the delivery and the goals of the two programmes. The DNSc in Europe is a taught degree in which students have to pass a range of examination and coursework milestones. In contrast, the $\mathrm{PhD}$ in Europe is non-taught and students do not have to meet such milestones. This pluralistic approach to Doctoral education is appropriate for the current stage of nursing development in Europe.

However, the programmes increasingly complement each other, with some $\mathrm{PhD}$ students attending modules for the DNSc students and the DNSc students attending seminars organised for $\mathrm{PhD}$ students. Both degrees are of equal rigour and both are systematically organised in terms of length of programme, supervision and support. Both are concerned with the training of students in research methods, the generation of new knowledge and the presentation of primary research in the form of a thesis, albeit for the DNSc, the thesis is much shorter. (See Figure 1 below).

Figure 1 Different approached to doctoral education in Europe

\begin{tabular}{llll}
\hline & \multicolumn{1}{c}{ DNSc } & \multicolumn{1}{c}{ PhD } & \multicolumn{1}{c}{ DPW/DP } \\
\hline $\begin{array}{l}\text { Delivery } \\
\text { Training }\end{array}$ & Taught & Non-taught & Non-taught \\
Orientation & Practice oriented & $\begin{array}{l}\text { Research } \\
\text { oriented }\end{array}$ & $\begin{array}{l}\text { Narrow } \\
\text { Research } \\
\text { oriented }\end{array}$ \\
Product & $\begin{array}{l}\text { Coursework, } \\
\text { examinations \& } \\
\text { thesis }\end{array}$ & Thesis only & $\begin{array}{l}\text { Series of peer } \\
\text { reviewed papers }\end{array}$ \\
Thesis & 15-20,000 words & $\begin{array}{l}\text { 100,000 words } \\
\text { Academic }\end{array}$ & $\begin{array}{l}\text { 50,000 words } \\
\text { Academic }\end{array}$ \\
Career & $\begin{array}{l}\text { Clinical/ } \\
\text { Advanced }\end{array}$ & $\begin{array}{l}\text { Faculty }- \\
\text { research \& } \\
\text { teaching and } \\
\text { health care } \\
\text { research roles }\end{array}$ & $\begin{array}{l}\text { Faculty research } \\
\text { and health } \\
\text { research roles }\end{array}$ \\
\hline
\end{tabular}

\section{Doctorate by published works}

There are three main routes to nurse doctoral preparation in Europe; the traditional $\mathrm{PhD}$ route, the professional doctorate route (e.g. DNSc), and the Doctorate by Published Works (DPW) or Doctorate by Publication (DP). While offered by many universities, the latter route is less common in nursing than the former paths. The exceptions to this is in a few countries such as Scandinavia and South Africa. The following example outlines the DPW approach: a student decides to research the effect of family therapy on attention deficit disorder. They will undertake the study in a similar way to that of other doctoral students. However, the thesis or dissertation is composed of 6-8 publications in peer-reviewed journals on the topic. Typically, an introductory chapter, not unlike a literature review, incorporating the rationale for the study, its relevant theories and research, supports these papers. There is also a closing chapter that brings forth conclusions, implications and recommendations from the publications.

In the UK, senior nurse educators who may not have had the opportunity to undertake a $\mathrm{PhD}$ at an early stage of their careers often under take DPWs. Over the years, they have accumulated some publications and, depending on current relevance, these are incorporated into a DPW. UK nurse scholars in the early stages of their careers seldom undertake such doctorates. For those who have embarked on a DPW, their university must ensure that the three outcomes of doctoral education outlined above are followed. The faculty must have credibility through being doctorally prepared, being involved actively in high quality research, having obtained grants from the most prestigious funders, having published in the top 10\% of journals in their field and having collaborated with international centres of excellence.

In some European countries, including the UK and Ireland, the DPW and the DNSc are perceived, rightly or wrongly, as having lower worth in the academy. Most scholars, universities schools and organisations hold up the research $\mathrm{PhD}$ as the gold standard of doctoral education. It is my opinion that in those countries where nursing is at an early stages of building a scholarly base and a reputation for itself in the academy, the research $\mathrm{PhD}$ route to doctoral education is the best approach.

\section{Conclusion}

In Europe, the move to doctoral education for nurses has its dissenters. These are mostly physicians or nurses who feel that nursing is moving too fast, leaving behind what they erroneously perceive to be important clinical tasks. However, no person, profession or organisation has the right to fix a boundary to the march of a discipline. They do not have a right to say this far and no further! The doctoral education journey for nursing is evolving and we must continue to generate and test the essential knowledge and skills of our discipline to ensure the betterment of care to patients, their families and communities. 
This has implications for African academic nursing. Being a relatively new entrant to higher education, nursing in Africa will be judged internationally by what is accepted as scholarship by more established disciplines. In my view, the traditional research $\mathrm{PhD}$ programme will be the most appropriate model for Africa. However, to adopt it as the gold standard there needs to be a critical mass of properly credentialed faculty members with active programmes of funded research, international collaborations and publications in the top tier of peerreviewed journals.

\section{References}

1. Hicks C. The dilemma of incorporating research into clinical practice. British Journal of Nursing 1997; 6(9), 511-515.

2. Lanara VA. The contribution of nursing research to the development of the discipline of nursing in Europe. Proceedings from the 7th Biennial Conference. Published by the Workgroup of European Nurse Researchers. Oslo 1994 (Jul 3-6) pp33-4

3. Traynor M. Personal Communication. London, Centre for Policy in Nursing Research, 1997.

\section{Further reading}

4. Kim, M.J. Park, C.G. McKenna, H.P. Ketefian, S. Park, SH. Klopper, H. Lee, H. Kunaviktikul, W. Gregg, M.F. Daly, J. Coetzee, S. Juntasopeepun, J. Murashima, S. Keeney S. Khan, S. Quality of nursing doctoral education in seven countries: survey of faculty and students/graduates. Journal of Advanced Nursing 2015;70(7), 1639-1652. DoI10.1111/ jan.12326

5. McKenna H.P, Keeney S., Kim M. J. \& Park C. G. Quality of doctoral nursing education in the United Kingdom: Exploring the views of doctoral students and staff based on a cross-sectional questionnaire survey. Journal of Advanced Nursing 2014;70(7), 16391652.

6. Kim MJ, McKenna HP, Ketefian S. Global quality criteria, standards, and indicators for doctoral programs in nursing; literature review and guideline development. Int J Nurs Stud, 2006;43(4),477-89.

7. McKenna, H.P. Doctoral Education: some thoughts. (Editorial) International Journal of Nursing Studies 2005; 42 (3), 245-246

8. McKenna, H.P. Cutcliffe, J.R. Nurse Doctoral Education in The United Kingdom And Ireland Online Journal of Issues in Nursing.2001;Vol.5, No2, http://www.nursingworld.org/ojin/topic12/ tpc12_9.htm

9. McKenna, H.P. Cowman, S . Doctoral Education in Nursing: an expanding phenomenon. Editorial. All Ireland Journal of Nursing and Midwifery 2001;2(2)

10. Ketefian, S. McKenna, H.P. Doctoral Education in Nursing: an internationalperspective. Routledge, London, 2004.

11. McKenna, H.P. Galvin, K. Doctoral processes: the scholarly practitioner. In Freshwater, D Bishop, V. (Eds) Nursing Research in Context: Appreciation, Application and Professional DevelopmentPalgraveMacmillan Chapter 6; p 93-117, 2004. 